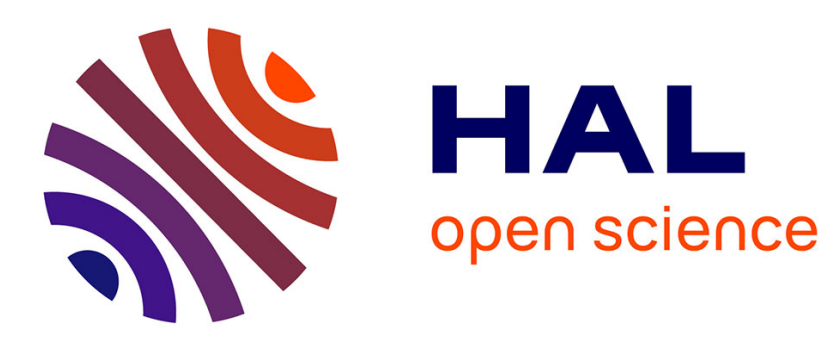

\title{
Wasp waist and flight: convergent evolution in wasps reveals a link between wings and body shapes \\ Adrien Perrard
}

\section{To cite this version:}

Adrien Perrard. Wasp waist and flight: convergent evolution in wasps reveals a link between wings and body shapes. American Naturalist, 2020, 195 (2), pp.181-191. 10.1086/706914 . hal-02495574

\section{HAL Id: hal-02495574 \\ https://hal.sorbonne-universite.fr/hal-02495574}

Submitted on 2 Mar 2020

HAL is a multi-disciplinary open access archive for the deposit and dissemination of scientific research documents, whether they are published or not. The documents may come from teaching and research institutions in France or abroad, or from public or private research centers.
L'archive ouverte pluridisciplinaire HAL, est destinée au dépôt et à la diffusion de documents scientifiques de niveau recherche, publiés ou non, émanant des établissements d'enseignement et de recherche français ou étrangers, des laboratoires publics ou privés. 


\title{
Wasp waist and flight: convergent evolution in wasps reveals a link between wings and body shapes
}

Adrien Perrard ${ }^{1,2}$

1) Institut d'Ecologie et des Sciences de l'Environnement, iEES Paris, Sorbonne Université, CNRS, INRA, IRD, UPEC, F-75005 Paris, France

2) Université de Paris, IEES, F-75005 Paris, France

adrien.perrard@univ-paris-diderot.fr

Insect flight; morphological integration; convergence; geometric morphometrics; Vespidae.

'The American Naturalist', manuscript accepted September 24, 2019. https://doi.org/10.1086/706914

\begin{abstract}
Insect flight is made possible by different morphological structures: wings produce the lift, the thorax drives the wings' movements and the abdomen serves as a secondary control device. As such, the covariation of these structures could reflect functional constraints related to flight performances. This study examines evolutionary convergences in wasp body shapes to provide the first evidence for morphological integration among insect wings, thorax and abdomen. Shapes of the fore- and hindwings, thorax and petiole (connecting abdomen and thorax) of 22 Vespidae species were analyzed using computerized tomography and geometric morphometrics. Results show a clear relationship between petiole and wings or thorax shapes, but not between wings and thorax. Wasps with elongated bodies have pointed wings, both features thought to improve flight maneuverability. In contrast, stouter species have rounded wings, which may allow for higher flight speeds. These integration patterns suggest that multiple selective regimes on flight performance, some of them biased towards maneuverability or maximal speed, drove the morphological diversity in Vespidae. The results also suggest that wing shapes evolved under constraints related to the body type they have to lift. The abdomen morphology is thus another factor to take into account to understand the flight performance of insects.
\end{abstract}




\section{Background}

The relationship between morphological forms and flight performance in insects is one of the current challenges of functional biology (Dudley 2002; Young et al. 2009; Mountcastle and Combes 2013; Shyy et al. 2016). Recently, models and empirical data have confirmed the importance of the shape of the wing in flight performance (Young et al. 2009; Mountcastle and Combes 2013; Shyy et al. 2016; Ray et al. 2016; Fraimout et al. 2018; Le Roy et al. 2019). However, wings are not the only structure involved in flight: the thorax contains the muscles that drive wing movement, providing both power and control of lifts (Matsuda 1970; Walker et al. 2014), and the abdomen is thought to play an important role in flight stability (Götz et al. 1970; Dyhr et al. 2013). Several studies explored the effect of general morphology on flight, such as the overall body size or the proportion of flight muscles (Outomuro et al. 2011; Garcia and Sarmiento 2012; Polidori et al. 2013), but no study has explored how the morphology of these different structures co-varies, which may provide insight into their influence on flight performance. Using morphological integration as a framework, this study examines the relationship between wings and body shape in vespid wasps.

Morphological integration, when different body parts vary in a coordinated manner, explains how variable features in organisms can develop into coherent, functional morphological units (Olson and Miller 1958; Cheverud 1996). Morphological integration acts both on sizes and shapes of body parts that are involved in the same function or that are related during development (Klingenberg 2014). Estimated by covariation patterns among structures, it provides an interesting framework for exploring the evolution and the function of different morphologies (Monteiro et al. 2005; Klingenberg and Marugan-Lobon 2013; Claverie and Patek 2013). Evolutionary integration, a pattern of covariation among traits that is observed across different species, may result from three main processes: developmental linkage, functional linkage, and shared ancestry. Developmental linkage is caused by pleiotropic genes or signaling pathways that may affect the morphology of multiple structures during the development. Functional linkage is due to the co-evolution of structures involved in the same function, as genes coding for these structures may evolve in a correlated fashion because they are under the same selective pressures. Shared ancestry affects the covariation of 
different structures because of the non-independence of lineages which induces a structure in combination of traits (Klingenberg and Marugán-Lobón 2013). The latter can be taken into account through phylogenetic comparative methods (Adams and Felice 2014). It is more difficult to disentangle developmental and functional linkages, since the former can be the product of natural selection on the latter. It is nonetheless possible to infer the existence of a functional linkage of shapes: morphological shapes are highly multivariate traits (Mezey and Houle 2005; Zelditch et al 2012), while only a subset of shape variation can be related to a specific function. As a result, a significant covariation between two or more shapes is unlikely to involve shape features related to a similar function in absence of functional linkage.

In addition, if there is a functional linkage, the shapes could evolve either in concert or in opposition relative to their functional performance. If some species are under stronger selective pressures for a function than others, for example because they experience a different selective optimum due to a different environment, then we could expect all of their structures' shapes to be linked to better performances for the function. It would result in a covariation of shapes related to the same variation in performance. On the contrary, the functional performance could have a single optimum for the different species. In this case, we can expect a trade-off between shapes: a variation of one shape impacting the performance should be linked to a variation of the other shape impacting the performance in an opposite way. Therefore, the analysis of covariation patterns among the wings, thorax and abdomen of insects may help us test whether those morphological structures evolved under a strong influence of selective forces on flight performances and whether those forces varied among species.

Wasps are an excellent model for exploring the influence of body shape on flight for two reasons: the structure of their body helps define clear functional modules, and the repeated acquisition of similar body shapes in different lineages improves the statistical power of comparative analyses on these traits (Felsenstein 1985; Fig. 1). The famous waist of wasps, caused by a constriction of the second abdominal segment, clearly separates two morphological modules related to flight: the mesosoma (hereafter called 'thorax') which contains the flight muscles, and the metasoma ('abdomen') which is thought to play a role 
in flight stabilization. Furthermore, wasps have repeatedly developed drastically different body types with an extreme elongation (i.e. Belonogaster, Eustenogaster) or shortening (i.e. Dolichovespula, Brachygastra) of the first metasomal segment (the 'petiole'). Thanks to the repeated evolution of this morphology in several groups, it is possible to disentangle covariation patterns caused by functional or developmental constraints from those induced by shared ancestry (Felsenstein 1985).

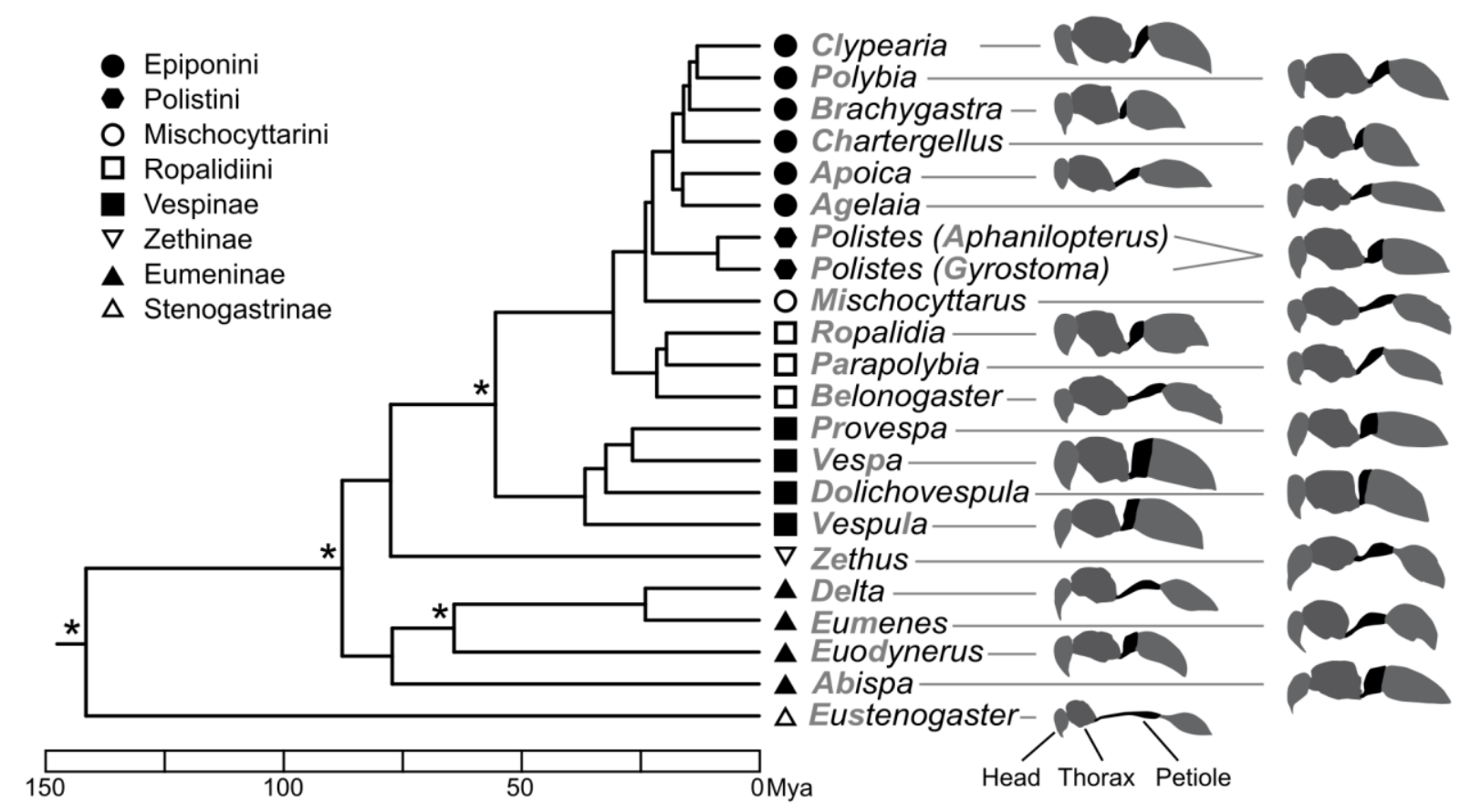

Figure 1. Calibrated tree of the main lineages of Vespidae with corresponding silhouettes. The phylogeny is based on the tree from 235 loci from Piekarski et al. 2018. Asterisks signal the four nodes used to calibrate the tree, according to branch lengths and the current knowledge about fossils of the group. Parameters used for the calibration are described in the appendix. Silhouettes are in lateral view, wings and antenna not represented. The petiole is in black. Due to the high discrepancies of sizes among the genera, the silhouettes are shown at different scales. Dot shapes are used in following figures to identify the main lineages.

Insect flight performance can be broadly divided into two main categories: traits related to power and traits related to maneuverability, the latter being the ability to perform quick changes in direction. A study on Drosophila wings shows that mutants with pointed wings have increased maneuverability, while natural individuals with more rounded wings can reach slightly higher speeds during straight forward flight (Ray et al. 2016). Furthermore, petiole elongation in wasps shifts the abdomen mass further away from the center of the insect. Such a change increases the moment of inertia for abdominal movements, increasing the 
efficiency of these movements for flight control, maximizing maneuverability (Berwaerts et al. 2002). In contrast, species with a stout petiole present a bullet-like silhouette, with the dorsal part of the thorax being in direct alignment with that of the abdomen (i.e. Vespa, Fig. 1). The body shape is known to affect the drag coefficients of insects, which becomes important at high speed, reaching $35 \%$ of the lift forces in bees (Nachtigall and Hanauer-Thieser 1992; Willmott and Ellington 1997). This drag is actively minimized by a change of posture of the abdomen during flight, highlighting its importance in insect flight (Taylor et al. 2013). Therefore, the bullet-like silhouette observed in honeybees and in some wasps could improve the aerodynamic characteristics of the insects, maximizing its speed. Finally, the thorax contains the flight muscles. In insects with asynchronous muscles (such as wasps), the wings, muscles and thorax act as a resonant structure that drives wing motion (Pringle 1957; Dudley 2002). A narrow thorax (i.e. Eumenes), which has proportionately larger dorso-ventral and antero-posterior flight muscles, is likely to produce a larger wing stroke amplitude as compared a flatter thorax (i.e. Zethus). Stroke amplitude is directly related to power output (Sane and Dickinson 2001), so a narrow thorax could maximize speed. The shape of wings, thorax and petiole could thus affect flight speed and maneuverability.

Since speed and maneuverability are involved in different ecological aspects of flight, different selective pressures may influence the evolution of the corresponding traits (Le Roy et al. 2019). Those two sets of traits could evolve in synergy, some species presenting either higher or lower overall flight abilities. They could also evolve independently; one set of traits being influenced by selective pressures without affecting the other. Finally, similar traits may influence both power and maneuverability in opposite ways, creating a trade-off. Such a trade-off on flight performances has been inferred in previous works on different insects (Lehmann \& Dickinson 2001; Ray et al. 2016; Le Roy et al. 2019). It may have had an impact on the evolution of wing and petiole shapes which affect both speed and maneuverability: a pointed wing (high maneuverability) cannot be apically rounded at the same time (high speed) (Ray et al., 2016). Neither can an elongated petiole (high maneuverability) minimize drag forces as a stout petiole would by matching thorax and abdomen profiles (high speed) (Nachtigall and Hanauer-Thieser 1992). 
We can therefore identify different scenarios that would produce different covariation patterns in these shapes. If the traits are not selected, there should be no significant covariation of the structures involving the shape features related to the flight performances (Figure 2A). However, if all species are under the same selective regime on flight, we can expect a trade-off between shapes towards an optimized ratio of speed to maneuverability, which should produce a significant covariation between traits (Figure 2B). If there are two selective regimes maximizing either speed or maneuverability, we should observe a group at each end of the features' spectra, which would create another covariation pattern between traits (Figure 2C). Finally, the species may evolve under more than two regimes, with different optima towards more or less balanced flight performances (Figure 2D). In this case, we would still be able to distinguish between the main influence of strong extreme optima versus a more balanced one by the sign of the covariation. They could also create a complex pattern with no significant interaction or even with two significant trends of opposite signs in different dimensions, since the traits are multivariate.
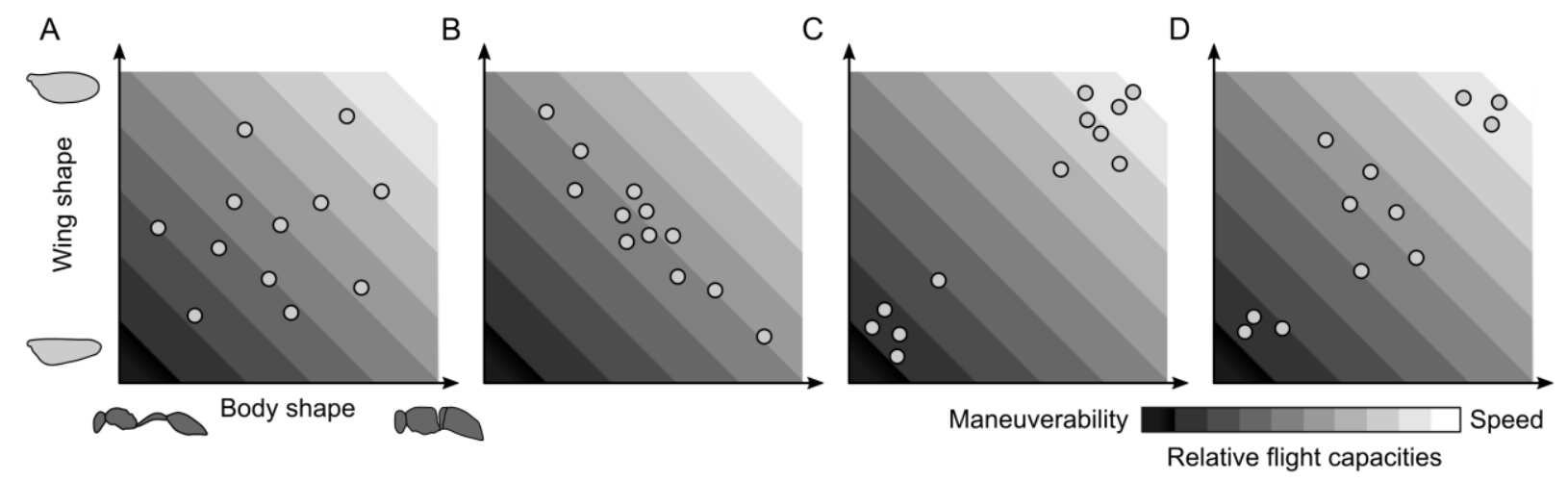

Figure 2. Potential models of integration of wing and body shapes considering their link to flight capacities (maximum speed and maneuverability). X-axes depict body shapes and Y-axes depict wing shapes. Shades of grey signal the relative flight capacity linked to the combination of shapes. Dots depict the shapes of fictive wasps under the different models. A. No selective optimum between speed and maneuverability. B. Single selective optimum on flight capacities inducing a negative covariation between wing and body shapes. C. Two specific optima favoring either speed or maneuverability, inducing a positive covariation between wings and body shapes. D. Three optima.

In this study, I therefore tested (1) whether there is a significant covariation between wing and body shapes,

(2) whether such covariation involves shape features related to maximizing flight speed or maneuverability,

(3) whether the patterns of covariation suggest a single or more complex selective regimes on flight 
performances in these wasps and (4) whether evolutionary shape convergences could explain extreme petiole, thorax and wing shapes.

To do so, the shape of the fore- and hindwings, thorax and petioles of 22 wasp species were quantified and analyzed in a phylogenetic framework using geometric morphometrics. The selective regimes were explored by testing whether co-varying traits maximize different flight performances or a same one. The latter case would suggest at least two selective optima on flight performances (Figure 2C), more if there are intermediate trait values (Figure 2D). The results reveal complex patterns of covariation among wings, petiole and thorax shapes. They suggest that the wings evolve under functional constraints related to the body type they lift, and that wasps have experienced different selective pressures related to flight performance during their evolution.

\section{Material and Methods}

The morphological variation studied is mostly visible among subfamilies and tribes. The variation of wing and body types is comparatively low within most tribes and genera, and was considered negligible at the species level. Furthermore, the main variation within genera and species can be related to size (e.g. Garcia and Sarmiento 2012). In order to focus the analysis on the shifts of body types while taking into account for these allometric effects, couples of large and small species were selected for each body type per lineage in the four main subfamilies of Vespidae whenever it was possible. For each of the 22 species selected, one female specimen was sampled from the alcohol collections of the American Museum of Natural History, New York (USA), and the Muséum National d'Histoire Naturelle, Paris (France) (voucher information in Appendix A).

Specimens were prepared using critical-point drying. Volume data were obtained using high resolution Xray $\mu \mathrm{CT}$-scan with a GE Phoenix Vtome xs $240 \mu \mathrm{CT}$ in the Microscopy and Imaging Facility of the AMNH. Specimens were scanned with voltage of 50 to $90 \mathrm{kV}$, current of 180 to $200 \mu \mathrm{A}$, and voxel size between $10.1 \mu \mathrm{m}$ and $25.8 \mu \mathrm{m}$. Three-dimensional processing and rendering were performed after semi-automatic 
segmentation, using Visual Graphics Studio Max program version 2.2 (Volume Graphics GmbH, Heidelberg, Germany). Surface (STL) files of the mesosoma ('thorax') and the first tergum of the metasoma ('petiole') were produced. Landmark coordinates were recorded on these surface data using Landmark editor (Appendix B) (Wiley et al. 2005). Because few homologous landmarks could be placed on the dorsal side of the petiole, its shape was also described by 12 sliding semi-landmarks.

Right wings were removed from the specimens, flattened between microscopic slides and photographed using a Microptics system. Wing landmark coordinates were recorded using TPSdig2 (Rohlf 2010). The wing shape was characterized using landmarks at the vein intersections and semi-landmarks. These semilandmarks were recorded along the edge of the wing, on the costal vein, between the pterostigma and the tip of the anal vein of the forewing and between the $\mathrm{R} 1$ and the $\mathrm{Cu}$ veins of the hindwing (Appendix B).

Shapes were estimated by the aligned coordinates of landmarks. Landmarks of each structure were aligned using Generalized Procrustes superimpositions minimizing Procrustes distances (Dryden and Mardia 1998). Thorax and petiole shapes were symmetrized before alignments. The sliding of 3D semi-landmarks of the petiole was first performed with the 'slider3d' function of the 'Morpho' package of R (R Core Team 2019; Schlager 2016). This function enabled the landmarks to slide directly onto the surfaces instead of using tangent planes as estimates (Gunz et al. 2005). Because this function minimizes the bending energy as superimposition criterion, petiole landmarks were realigned after the sliding of semilandmarks using Procrustes distances. Wing and body shape variation of each structure was explored independently, using Principal Components Analyses (PCA) of the aligned coordinates with the phylogeny mapped on each morphospace.

Due to physical constraints, size may have an influence on shapes, and thus on the shape integration among structures (Gould 1966; Garcia and Sarmiento 2012). Allometry, the influence of size on shape, was tested using multivariate linear regressions of size on the shape of each measured structure. Log-transformed dry weight, measured using an electronic scale $(0.001 \mathrm{~g}$ precision $)$, was used as a general estimate of specimen 
size. When allometry was significant, analyses of the corresponding structure were also performed on the regression residuals.

The phylogeny was taken into account to remove the covariation due to shared ancestry. Relationships between the species were based on the Maximum-Likelihood tree inferred from 235 loci from Piekarski and collaborators (2018), which included all 22 genera and subgenera studied here. When the exact species were not included in the phylogeny, their relationships were estimated by the closest species from the same genus or subgenus in the phylogeny (Appendix C). This way, 22 species were selected among the 163 taxa of the phylogeny, and the rest were pruned from the tree. As comparative methods are best performed on time-calibrated trees, the resulting phylogeny was calibrated using the chronos function from the 'ape' library (Paradis et al. 2004, see Appendix C for parameters used for time calibration).

The phylogenetic signal of these data was tested independently for each dataset using the multivariate extension of the $\mathrm{K}$ of Blomberg (Adams 2014). Morphological integration of shapes of the different structures was then tested using pairwise phylogenetic Partial Least Squares (pPLS) based on Brownian motion model of evolution (Adams and Felice 2014). Pairwise comparisons were applied for the abdomen, the thorax, and the forewing and hindwing combined. For comparison, morphological integration was also investigated between fore and hindwings, as these two structures have a clear functional interaction during flight. These covariation patterns were then compared using their effect size with the compare.pls function (Adams and Collyer 2016). The sensitivity of the pPLS results was tested by removing one, two or three taxa from the analysis for all possible subsampling combinations (22, 231 and 1540 replicates). With the exception of the sliding of 3D semilandmarks, morphometric and comparative analyses were performed with R, using the 'geomorph' package v. 3.0.6 (Adams et al. 2018).

Finally, the functional link between shapes was further tested by assessing the evolutionary convergence in petiole, thorax and wing shapes for taxa with similar morphologies. Shape convergence was tested by comparing the number of times a set of taxa reached a combination of shapes (nl) to the number of times it would happen under neutral evolution using simulations under brownian motion model of evolution 
(Stayton, 2015). Shape convergence was assumed if lineages reached independently a similar combination of wing, thorax and body shapes more often than expected under neutral evolution. Data from the three shapes were combined so that the variation of each shape was equivalent in the resulting morphospace. Convergence was tested for the eight short-petiole taxa (Provespa, Vespa, Vespula, Dolichovespula, Brachygastra, Chartergellus, Euodynerus, Abispa) and the seven long-petiole taxa (Eumenes, Eustenogaster, Mischocyttarus, Belonogaster, Parapolybia, Delta and Zethus) with the 'convnumsig' function of the 'convevol' package with 10000 simulations (Stayton and Stayton 2018). Since the test has to be performed on less dimensions than there are putative convergent taxa, analyses were performed on the six first principal components of the PCA on the three shapes combined.

Hypotheses were tested with a risk alpha (false-positive) of $5 \%$.

Landmark data, surface data and the R script used to perform these analyses and figures are deposited in the Dryad Digital Repository: http://doi.org/10.5061/dryad.4f30fn5 (Perrard 2019).

\section{Results}

Most of the variation in petiole shape $(86.73 \%)$ was explained by the first principal component (PC), which mainly describes the elongation of the segment (Figure 3.A). The second axis described an antero-posterior displacement of the widening of the segment, either at the very base (i.e. Vespa) or near the apex (i.e. Zethus). It explained much less of the variation $(5.48 \%$, then $2.56 \%, 1.58 \%$ and $1.18 \%$ for the following PCs). In contrast, seven PCs were required to explain an amount of variation of wings and thorax shapes similar to the variation described by the first PC of petiole shapes, highlighting the high dimensionality of these data. Wing data were grouped according to the main lineages of the sample, suggesting a strong phylogenetic effect (Figure 3.B). The first wing PCs explained 31.86\%, 18.56\%, 15.32\%, 8.51\%, 7.00\%, $5.33 \%, 2.97 \%$ then $2.45 \%$ of the wing shape variation. The two first PCs of thorax shapes also suggested a phylogenetic effect (Figure 3.C). These two PCs described a dorso-ventral flattening and an antero-posterior 
elongation of the thorax. They accounted for $53.6 \%$ of thorax shape variation, and short petiole taxa were grouped toward central and negative values, suggesting a link between petiole and thorax shapes.
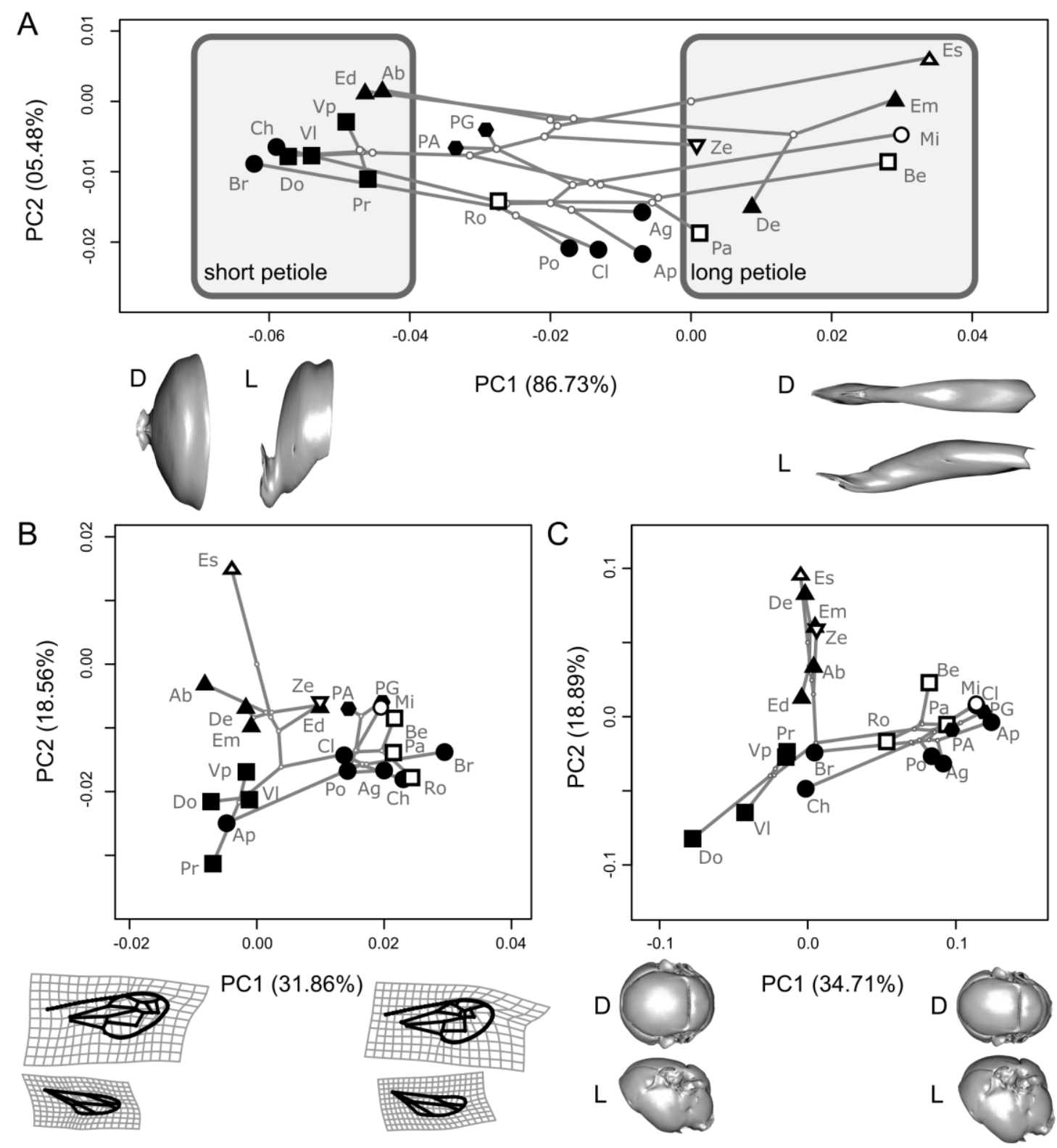

Figure 3. Two first principal components (PC) of the phylomorphospaces of the three investigated shapes with depiction of the shape changes along each first PC. A: Petiole shape with mention of taxa with short petiole and long petiole. B: Wings shapes. C: Thorax shapes. Percentage of the total shape variation explained by each component is mentioned on each axis. D: Dorsal view. L: Left lateral view. The shape and color of the points discriminate the main lineages (list in Figure 1). Cl: Clypearia; Po: Polybia; Br; Brachygastra; Ch: Chartergellus; Ap: Apoica; Ag: Agelaia; PA: Aphanilopterus; PG: Gyrostoma; Mi: Mischocyttarus; Ro: Ropalidia; Pa: Parapolybia; Be: Belonogaster; Pr: Provespa; Vp: Vespa; Vl: Vespula; Do: Dolichovespula; Ze: Zethus; De: Delta; Em: Eumenes; Ed: Euodynerus; Ab: Abispa; Es: Eustenogaster. 
Significant allometry was identified in forewing and combined wing shapes (Table 1). Analyses on these structures were performed on raw data and allometric residuals.

Table 1. Allometry of wasp body and wings shapes.

\begin{tabular}{|c|c|c|c|c|c|}
\hline Body part & Size SS & Residuals SS & $\mathrm{F}$ & $\mathrm{Z}$ & $p$ \\
\hline Thorax & 0.00588 & 0.21594 & 0.5448 & -0.96884 & 0.835 \\
\hline Petiole & 0.13257 & 2.30446 & 1.1506 & 0.64261 & 0.285 \\
\hline Wings & 0.00107 & 0.00896 & 2.3955 & 1.99560 & $0.021 *$ \\
\hline Forewing & 0.00645 & 0.03979 & 3.2420 & 2.43790 & $0.005^{*}$ \\
\hline Hindwing & 0.01163 & 0.11438 & 2.0342 & 1.34604 & 0.089 \\
\hline
\end{tabular}

Note. $-\mathrm{SS}=$ Sum of Squares; $\mathrm{F}=$ value of the test $\mathrm{Z}=$ effect size; $p=$ probability. Allometry was estimated by a multivariate regression of log-transformed weight of specimens over the shape variables of each structure. Probabilities were estimated using a null distribution based on 10,000 resampling permutations. Degrees of freedom: size 1; residuals 20. * - Significant result $(p<0.05)$.

Each of the body parts presented a significant phylogenetic signal (thorax: $\mathrm{K}=0.568, \mathrm{P}=0.0002$; petiole: $\mathrm{K}=0.543, \mathrm{P}=0.0085$; wings: $\mathrm{K}=0.641, \mathrm{P}=0.0001)$. Phylogenetic $\mathrm{PLS}$ confirmed the link between thorax and petiole, and between fore-and hindwing. It also revealed a significant relationship between wings and petiole, but not between wings and thorax (Fig. 4, Supplementary material Table S1). In the latter relationship, the first pPLS axis only explained $34.6 \%$ of the total covariation between wings and thorax, while it explained $69.6 \%$ and $59.3 \%$ between petiole and thorax and between wings and petiole respectively. The effect sizes of the different covariation patterns were not significantly different. Petiole and thorax and fore- and hindwing relationships were robust to the removal of two random specimens, but were non-significant when removing certain combinations of three specimens $(0.5 \%$ and $0.2 \%$ of the combinations tested, respectively). The relationship between petiole and wing shapes was most affected by the removal of Mischocyttarus in raw data, but less so with allometric residuals of wing data: the 
removal of the other extreme, Brachygastra, was required to reach a non-significant relationship (Supplementary table S2).

Shape variation depicted by the first pPLS axes corresponded to shape variation that could be linked to flight performances (Supplementary information, Figures S1-3). In particular, longer petioles are found in taxa with a narrow, elevated thoraces, and with elongated wings pointed at the apex (Fig. 5).

The first 6 PCs of the PCA on the three shapes combined explained 82,96\% of the total shape variation. Over the course of their evolution, the lineages of the eight short-petiole taxa reached independently seven times a similar combination of thorax, abdomen and wing shapes, which is significantly more than expected under neutral evolution $(\mathrm{nl}=7, \mathrm{P}=0)$. The lineages of the eight short-petiole taxa also reached significantly more often a similar combination of thorax, abdomen and wing shapes than expected at random $(\mathrm{nl}=5, \mathrm{P}=0.0001)$. Wing, thorax and petiole shapes can therefore be considered as convergent among short petiole taxa and among long petiole taxa.

\section{Discussion}

These results revealed a complex pattern of morphological integration among body parts involved in flight in wasps. Shapes of thorax and petiole and of the fore- and hindwing present significant covariation. Wings and petiole shapes also presented a significant relationship, albeit less supported by the data, according to the subsample analysis. Surprisingly, the lowest level of integration was found between the shapes of thorax and wings. Finally, the shape of the thorax, wings and petiole seemed to have converged independently in at least two groups: long-petiole taxa and short-petiole taxa. These results confirm our first hypothesis that body and wing shapes are morphologically integrated. 


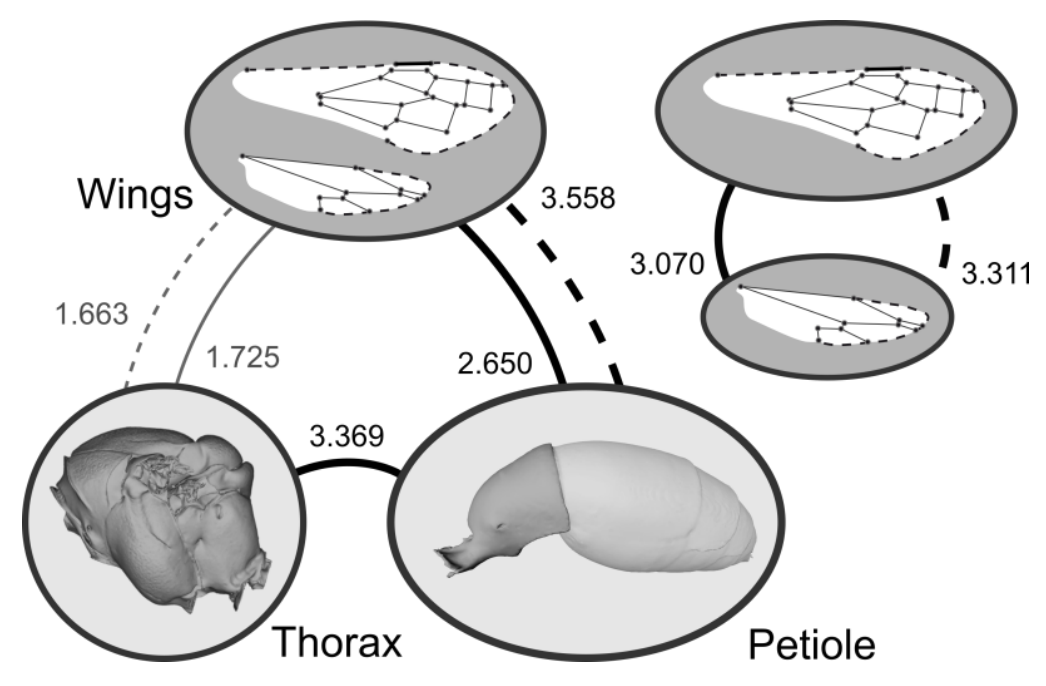

Figure 4. Results of the morphological integration analyses on the different pairs of structures related to flight using phylogenetic partial least squares (pPLS). Values are effect size computed with the compare.pls function. Grey lines: non-significant relationships. Black lines: significant relationships. Dotted lines: morphological integration based on allometric residuals for combined wings and forewing shapes.

The covariation patterns involved mostly shape changes related to flight capacities: a strong elongation of the petiole (high maneuverability) was linked to the narrow elevated thorax (high speed) and pointed wings (high maneuverability). The second and third PLS axes explained much less of the covariation and were associated to shape variation less easily linked to flight (Figures S1, S2 and S3). Considering the high dimensionality of wings and thorax shapes, these analyses suggest a functional linkage among the different structures.

Finally, the covariation patterns were different between wings and petiole compared to thorax. Wings and petiole shapes expressed a covariation pattern maximizing either speed or maneuverability (Fig 2.C-D), suggesting that the taxa experienced different selective pressures relative to their flight capacities. Alternatively, thorax shapes varied in an opposite way to wings and petiole shapes, regarding flight performances (Fig. 2.B). Such a difference could imply that the thorax shape and petiole and wing shapes evolved to balance flight speed and maneuverability. It may also come from a trade-off between thorax constraints related to flight muscles and constraints related to the muscles articulating the petiole, which are also rooted in the thorax (Short 1959; Hashimoto 1996). 


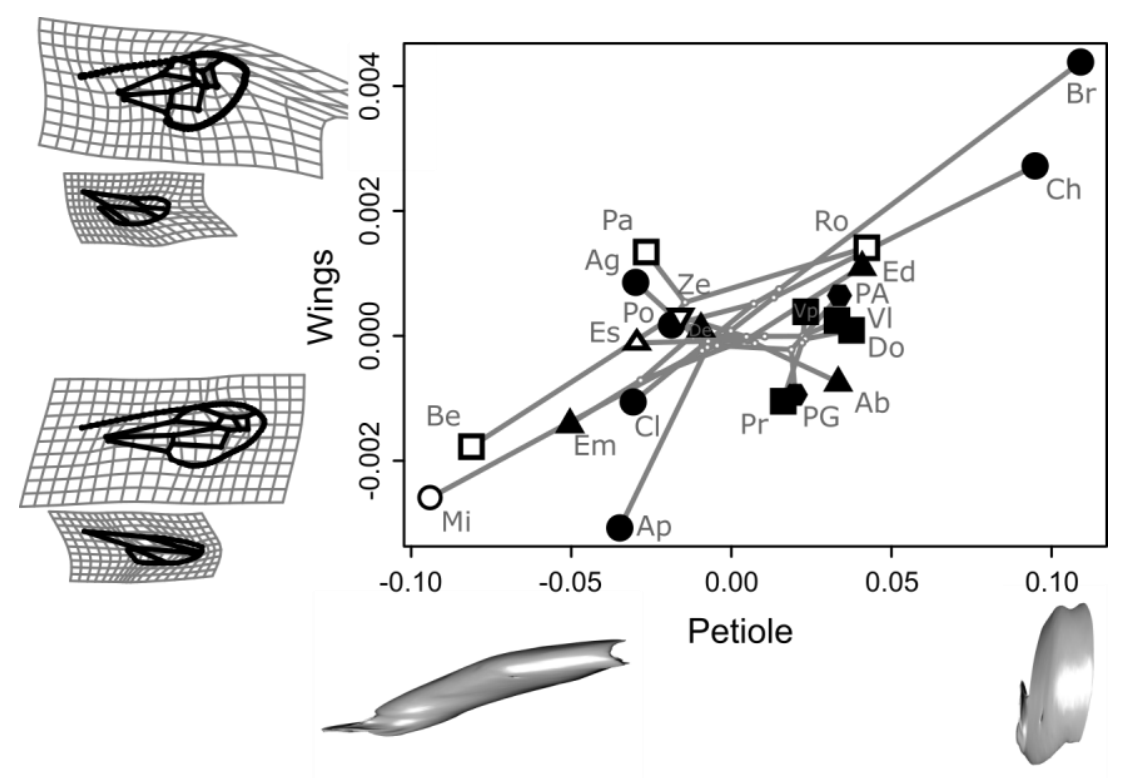

Figure 5. Plot of the first dimension of the phylogenetic partial least-square (pPLS) analysis between wing shapes and petiole shapes. Shape variation along the first pPLS axis of the petiole is depicted in lateral view, left side. Shape variation along the first pPLS axis of the fore and hindwings is depicted by two deformation grids and amplified twofold for better visualization. Phylogenetic relationships were mapped to illustrate that the covariation cannot be explained by the phylogeny. The shape and color of the points discriminate the main lineages (list in Figure 1). Cl: Clypearia; Po: Polybia; Br; Brachygastra; Ch: Chartergellus; Ap: Apoica; Ag: Agelaia; PA: Aphanilopterus; PG: Gyrostoma; Mi: Mischocyttarus; Ro: Ropalidia; Pa: Parapolybia; Be: Belonogaster; Pr: Provespa; Vp: Vespa; Vl: Vespula; Do: Dolichovespula; Ze: Zethus; De: Delta; Em: Eumenes; Ed: Euodynerus; Ab: Abispa; Es: Eustenogaster.

The absence of significant relationship between the thorax and wing shapes suggests a weaker link between these structures. Such an absence of significant relationship between thorax and wing shapes was previously found on a larger sample (Garcia and Sarmiento 2012). The thorax in itself is of major importance for flight because its own mechanical properties and the flight muscles it hosts drive wing movements (Dudley 2002). However, the mechanical properties of the thorax are not related solely to the external shape, but also to the configuration and shape of the axillary sclerites, the internal structures and the cuticular width of the different sclerites (Snodgrass 1910; Matsuda 1970). The external shape of the thorax may thus have a limited role in flight.

Considering the covariation between the petiole and wings shapes, the pattern was not driven by two clearly separated groups but a continuum of shapes (Fig. 5). Such a pattern would fit a model of evolution with more than two extreme adaptive peaks: only some of the taxa may have experienced strong selective pressures for enhanced speed (e.g. Brachygastra) or maneuverability capacities (e.g. Mischocyttarus) 
(Figure 2.D). Other taxa may have been either under the influence of selection for more balanced flight capacities, or did evolve under low selective pressures on the balance between these two components of flight performances.

The evidence of a functional link between wings and abdomen appears nonetheless limited by the sample size. In particular, Mischocyttarus exerts an unusually strong influence on the results (Fig. 5), probably because it has a greatly elongated petiole, yet is relatively closely related to the Epiponini with much shorter ones. It requires a greater evolutionary rate than estimated for other taxa with elongated petioles, such as Eustenogaster (Fig. 1), hence more weight in the pPLS analysis (Adams and Felice 2014). The significant relationship between wings and petiole seems nonetheless more robust when taking the forewing allometry into account. The weak difference in effect size with stronger relationships such as the one linking foreand hindwings also strengthens the biological relevance of the petiole-wings relationship.

While the link between petiole elongation and flight performances would require a proper kinematic study, several biological observations corroborate these results. For example, both Eustenogaster and Mischocyttarus are known for their remarkably stable flight: some are even able to steal food from spider webs in mid-air (Jeanne 1972; Turillazzi 1983). This contrasts with the infamous frantic flight of yellowjackets (Vespula) over food sources. Vespula and Brachygastra have stouter bodies and more rounded wings. They live in large nests, which suggests longer flight distances to forage. Since foraging efficiency would be important to feed a large nest, selective pressures may have favored speed in straight flight over maneuverability in the stouter wasps, while maneuverability would have been selected because it opens new resource niches in taxa with an elongated petiole.

Due to methodological constraints, this study focused on the shape of the first segment of the abdomen only. The entire abdomen could not be directly quantified because its segments are articulated and geometric morphometrics are best applied on rigid structures (Zelditch et al. 2012). The first metasomal tergum was the most variable abdominal structure in these wasps. It provided thus a consistent estimate of the main shape variation of the abdomen. 
The relationship between petiole and wing shapes has several implications for our understanding of insect flight and morphological evolution. First, it suggests that abdomen morphology could be an important parameter in insect flight. To date, most biomechanical studies of insect flight have focused on wing or thorax morphologies (e.g. Janet 1899; Snodgrass 1942; Dudley 2002; Shang et al. 2009; Young et al. 2009). Understanding abdomen's role in flight performance would be a key step toward understanding the biomechanics of insect flight, an important topic in the wake of the recent development in bio-inspired technologies (Shyy et al. 2016).

In addition, the forewing shape is increasingly used in systematics, as it can be useful for species identification (Dehon et al. 2014; Perrard et al. 2014). However, our results confirm that this marker is prone to homoplasy and should not be considered as entirely reliable for phylogenetic classification (Perrard et al. 2016).

Finally, this study provides insight into the scarcely understood role of the extremely elongated petioles that has evolved independently in several groups of insects, including wasps and flies. This trait appears as a clear convergence in vespid wasps and could be related to oviposition, since some of these insects lay their eggs in closed nests or small cells. It could also be related to predation since they prey on long insects such as caterpillars. A long abdomen would allow them to reach a distant target while keeping their head out of the cell or while grasping the prey with their mandibles (Turillazzi 1985; Budrys and Budriené 2012). Petiole elongation could also allow insects to transport large preys without compromising freedom of movement of the abdomen (Budrys and Budrienè 2012; Polidori et al. 2013). However, the diversity of morphologies and life traits of these insects suggests that petiole elongation may have another, more general function in insect flight. The covariation between wings and petiole shape and the convergence of body shapes in taxa with long or short petiole suggest that, at least in vespid wasps, selective pressures on flight performance may have played a role in the evolution of such extreme morphologies.

\section{Conclusions}


This study revealed a morphological integration between wings and petiole in wasps, which affected shape features that could be linked to flight performances. In contrast, while the thorax is clearly important for flight, there was no significant relationship between the overall shape of the thorax and that of the wings. Whether this result is due to conflicting constraints in thorax shape with those from legs and abdominal muscles or to the low importance of the overall shape of the thorax for flight remains to be explored. In any case, the stronger covariation between wings and petiole shapes highlights the potential importance of body shape for flight. The covariation patterns observed between wings and abdomen shapes also suggest multiple optima for the equilibrium between flight speed and maneuverability in these wasps. Abdomen morphology could therefore be one of the missing keys to understanding and to mimicking the astonishing flight performance of insects.

\section{Data accessibility}

The shape data and the R scripts used for the analyses are stored on the Dryad repository system: Dryad doi:10.5061/dryad.4f30fn5.

\section{Acknowledgements}

I am grateful to Morgan Hill, Henry Towbin, Tobias Schuh and the microscopy and imaging facility of the American Museum of Natural History for their help with the imaging and CT-scans of the specimens. I thank James M. Carpenter, Claire Villemant, Bernardo Santos and Alexander Somavilla for their help in gathering the specimens required for this study. I also thank Dean Adams, Stacey Combes, Florence Débarre, Camille Le Roy and Emilie Rault for their helpful discussions regarding this study. This manuscript was greatly improved thanks to the help of Scott J. Steppan and 4 anonymous reviewers. This study was funded by a Gerstner Scholarship and a Kalbfleisch fellowship from the American Museum of Natural History, and the Labex BCDiv from the Museum National d'Histoire Naturelle.

\section{References}


Adams, D. C. 2014. A generalized K statistic for estimating phylogenetic signal from shape and other high-dimensional multivariate data. Systematic Biology 63:685-697.

Adams, D.C. and M.L. Collyer. 2016. On the comparison of the strength of morphological integration across morphometric datasets. Evolution 70(11):2623-2631.

Adams, D. C., and R. N. Felice. 2014. Assessing trait covariation and morphological integration on phylogenies using evolutionary covariance matrices. PloS One 9:e94335.

Adams, D. C., Collyer, M. L. and A. Kaliontzopoulou. 2018. Geomorph: Software for geometric morphometric analyses. R package version 3.0.6. https://cran.r-project.org/package=geomorph.

Berwaerts, K., H. Van Dyck, and P. Aerts. 2002. Does flight morphology relate to flight performance? An experimental test with the butterfly Pararge aegeria. Functional Ecology $16: 484-491$.

Budrys, E., and A. Budrienè. 2012. Adaptability of Prey Handling Effort in Relation to Prey Size in Predatory Wasps (Hymenoptera: Eumeninae). Annales Zoologici Fennici 49:58-68.

Carpenter, J. M. 1982. The phylogenetic relationships and natural classification of the Vespoidea (Hymenoptera). Systematic Entomology 7:11-38.

Cheverud, J. M. 1996. Quantitative genetic analysis of cranial morphology in the cotton-top (Saguinus oedipus) and saddle-back (S. fuscicollis) tamarins. Journal of Evolutionary Biology 9:5-42.

Claverie, T., and S. N. Patek. 2013. Modularity and rates of evolutionary change in a poweramplified prey capture system. Evolution 67:3191-3207.

Dehon, M., D. Michez, A. Nel, M. S. Engel, and T. De Meulemeester. 2014. Wing shape of four new bee fossils (Hymenoptera: Anthophila) provides insights to bee evolution. PloS One 9 .

Dryden, I. L., and K. V. Mardia. 1998. Statistical shape analysis (Vol. 4). Wiley, Chichester. 
Dudley, R. 2002. The biomechanics of insect flight: form, function, evolution. Princeton University Press, Princeton, NJ.

Dyhr, J. P., K. A. Morgansen, T. L. Daniel, and N. J. Cowan. 2013. Flexible strategies for flight control: an active role for the abdomen. Journal of Experimental Biology 216:1523-1536.

Felsenstein, J., 1985. Phylogenies and the comparative method. The American Naturalist 125:1-15.

Fraimout, A., Jacquemart, P., Villarroel, B., Aponte, D.J., Decamps, T., Herrel, A., Cornette, R. and V. Debat. 2018. Phenotypic plasticity of Drosophila suzukii wing to developmental temperature: implications for flight. Journal of Experimental Biology 221: p.jeb166868.

García, Z., and C. E. Sarmiento. 2012. Relationship between body size and flying-related structures in Neotropical social wasps (Polistinae, Vespidae, Hymenoptera). Zoomorphology 131:25-35.

Götz, K. G., B. Hengstenberg, and R. Biesinger. 1979. Optomotor control of wing beat and body posture in Drosophila. Biological Cybernetics 35:101-112.

Gould, S. J. 1966. Allometry and size in ontogeny and phylogeny. Biological Reviews 41:587638.

Gunz, P., P. Mitteroecker, and F. L. Bookstein. 2005. Semilandmarks in three dimensions. Pages 73-98 in Modern morphometrics in physical anthropology. Springer, Boston, MA.

Hashimoto, Y. 1996. Skeletomuscular modifications associated with the formation of an additional petiole on the anterior abdominal segments in aculeate Hymenoptera. 昆蟲 64:340-356.

Janet, C. 1899. Sur le mécanisme du vol chez les insectes. Comptes-Rendus de l'Académie des Sciences 128: 249-253.

Jeanne, R. L. 1972. Social biology of the neotropical wasp Mischocyttarus drewseni. Bulletin of the Museum of Comparative Zoology 144:63-150. 
Klingenberg, C. P. 2014. Studying morphological integration and modularity at multiple levels: concepts and analysis. Philosophical Transactions of the Royal Society B 369:20130249. Klingenberg, C. P., and J. Marugán-Lobón. 2013. Evolutionary covariation in geometric morphometric data: analyzing integration, modularity, and allometry in a phylogenetic context. Systematic Biology 62:591-610.

Lehmann, F.O., and M.H. Dickinson. 2001. The production of elevated flight force compromises manoeuvrability in the fruit fly Drosophila melanogaster. Journal of Experimental Biology 204:627-635.

Le Roy, C., Debat, V., and V. Llaurens. 2019. Adaptive evolution of butterfly wing shape: from morphology to behaviour. Biological Reviews 94:1261-1281.

Matsuda, R. 1970. Morphology and evolution of the insect thorax (Memoirs of the entomological society of Canada., Vol. 76). The Entomological society of Canada, Ottawa.

Mezey, J. G., D. Houle, and S. V. Nuzhdin. 2005. Naturally segregating quantitative trait loci affecting wing shape of Drosophila melanogaster. Genetics 169:2101-2113.

Monteiro, L. R., V. Bonato, and S. F. Dos Reis. 2005. Evolutionary integration and morphological diversification in complex morphological structures: mandible shape divergence in spiny rats (Rodentia, Echimyidae). Evolution \& Development 7:429-439.

Mountcastle, A. M., and S. A. Combes. 2013. Wing flexibility enhances load-lifting capacity in bumblebees. Proceedings of the Royal Society B: Biological Sciences 280:20130531.

Nachtigall, W., and Hanauer-Thieser, U. 1992. Flight of the honeybee. V. Drag and lift coefficients of the bee's body; implications for flight dynamics. Journal of Comparative Physiology. B, Biochemical, Systemic, and Environmental Physiology 162:267-277. 
Olson, E. C., and R. L. Miller. 1958. Morphological integration. University of Chicago Press, Chicago.

Outomuro, D., and F. Johansson. 2011. The effects of latitude, body size, and sexual selection on wing shape in a damselfly. Biological Journal of the Linnean Society 102:263-274.

Paradis, E., Claude, J., and Strimmer, K. 2004. APE: analyses of phylogenetics and evolution in R language. Bioinformatics 20:289-290.

Perrard, A., M. Baylac, J. M. Carpenter, and C. Villemant. 2014. Evolution of wing shape in hornets: why is the wing venation efficient for species identification? Journal of Evolutionary Biology 27:2665-2675.

Perrard, A., F. Lopez-Osorio, and J. M. Carpenter. 2016. Phylogeny, landmark analysis and the use of wing venation to study the evolution of social wasps (Hymenoptera: Vespidae: Vespinae). Cladistics 32:406-425.

Piekarski, P. K., Carpenter, J. M., Lemmon, A. R., Moriarty Lemmon, E., Sharanowski, B. J., and Crandall, K. 2018. Phylogenomic evidence overturns current conceptions of social evolution in wasps (Vespidae). Molecular Biology and Evolution 35:2097-2109.

Polidori, C., A. Crottini, L. Della Venezia, J. Selfa, N. Saino, and D. Rubolini. 2013. Food load manipulation ability shapes flight morphology in females of central-place foraging Hymenoptera. Frontiers in Zoology 10:36.

Pringle, J. W. S. 1957. Insect flight (Vol. 9). Cambridge University Press, Cambridge.

R Core Team. 2019. R: A language and environment for statistical computing (R Foundation for Statistical Computing.). Vienna, Austria.

Ray, R. P., T. Nakata, P. Henningsson, and R. J. Bomphrey. 2016. Enhanced flight performance by genetic manipulation of wing shape in Drosophila. Nature Communications 7:10851. 
Rohlf, F. J. 2010. tpsDig v2.16. Department of Ecology and Evolution, State Univ. of New York, Stony Brook, NY: Distributed by author. https://life.bio.sunysb.edu/morph/

Sane, S. P., and M. H. Dickinson. 2001. The control of flight force by a flapping wing: lift and drag production. Journal of experimental biology 204:2607-2626.

Schlager, S. 2016. Morpho: calculations and visualisations related to geometric morphometrics. R package version 2.3.1.1. https://cran.r-project.org/package=Morpho

Shang, J. K., S. A. Combes, B. M. Finio, and R. J. Wood. 2009. Artificial insect wings of diverse morphology for flapping-wing micro air vehicles. Bioinspiration and Biomimetics 4:36002.

Short, J. R. T. 1959. On the skeleto-muscular mechanisms of the anterior abdominal segments of certain adult Hymenoptera. Transactions of the Royal Entomological Society of London 111:175-203.

Shyy, W., C. Kang, P. Chirarattananon, S. Ravi, and H. Liu. 2016. Aerodynamics, sensing and control of insect-scale flapping-wing flight. Proceedings of the Royal Society A 472:20150712.

Snodgrass, R. E. 1910. The thorax of the Hymenoptera. Proceedings of the U.S. National Museum 39:37-91.

Snodgrass, R. E. 1942. The skeleto-muscular mechanisms of the honey bee. Smithsonian Miscellaneous Collections 103:1-120.

Stayton, C.T. 2015. The definition, recognition, and interpretation of convergent evolution, and two new measures for quantifying and assessing the significance of convergence. Evolution $69: 2140-2153$.

Stayton, C.T., and M.C.T. Stayton. 2018. Package 'convevol'. https://cran.rproject.org/package $=$ convevol 
Taylor, G.J., Luu, T., Ball, D. and M.V. Srinivasan. 2013. Vision and air flow combine to streamline flying honeybees. Scientific reports 3:2614.

Turillazzi, S. 1983. Extranidal Behaviour of Parischnogaster nigricans serrei (Du Buysson) (Hymenoptera, Stenogastrinae) 1. Zeitschrift für Tierpsychologie 63:27-36.

Turillazzi, S. 1985. Egg deposition in the genus Parischnogaster (Hymenoptera: Stenogastrinae). Journal of the Kansas Entomological Society 58:749-752.

Walker, S. M., D. A. Schwyn, R. Mokso, M. Wicklein, T. Müller, M. Doube, M. Stampanoni, et al. 2014. In vivo time-resolved microtomography reveals the mechanics of the Blowfly flight motor. PloS Biology 12:e1001823.

Wiley, D. F., N. Amenta, D. A. Alcantara, D. Ghosh, Y. J. Kil, E. Delson, W. Harcourt-Smith, et al. 2005. Evolutionary morphing. Pages 431-438 in Visualization, 2005. VIS 05. IEEE. IEEE.

Willmott, A. P., and Ellington, C. P. 1997. The mechanics of flight in the hawkmoth Manduca sexta. II. Aerodynamic consequences of kinematic and morphological variation. Journal of Experimental Biology, 200:2723-2745.

Young, J., S. M. Walker, R. J. Bomphrey, G. K. Taylor, and A. L. Thomas. 2009. Details of insect wing design and deformation enhance aerodynamic function and flight efficiency. Science 325:1549-1552.

Zelditch, M.L., Swiderski, D.L. and H.D. Sheets 2012. Geometric morphometrics for biologists: a primer. Academic Press, New York, NY. 
Appendix. Voucher information, landmark location and methods of phylogeny reconstruction and time-calibration.

The 22 specimens measured in the study were retrieved from the alcohol collection of the Invertebrate Zoology department of the American Museum of Natural History (Table A1). For each specimen, the mesosoma was quantified using 26 landmarks, the petiole using 10 landmarks and 12 surface semilandmarks, the right forewing using 23 landmarks and 63 semi-landmarks along the outline of the wing, and the right hindwing using 11 landmarks and 28 semi-landmarks (Fig. A1).

Table A1. Voucher information

\begin{tabular}{lllllr} 
Genus & species & Country & Locality & date & year \\
\hline Eustenogaster & calyptodoma & Malaya & Ulu Gombak, univ. & 1-viii & 1982 \\
Delta & latreillei & Australia & Charles Darwin U., 15km N. Katherina & 19-ix & 2009 \\
Euodynerus & leucomelas & USA & NY, Ulster Co., Shandaken & 29-vii & 2006 \\
Abispa & ephippium & Australia & Queensland, Townsville, Belgian Gardens & 6-ii & 2006 \\
Eumenes & sp. & Thailand & Trang Nayong, Khaozong Lab & 1-4-ix & 2006 \\
Zethus & slossonae & USA & Fl. Dade Co. Montgomery Bot. Cent. & 23-i & 2009 \\
Dolichovespula & arenaria & USA & CA, Sagehen Creek near Truckee - MT & 2-vi & 2003 \\
Vespa & affinis & Nepal & Terai, Gaindakot, Nawalparasi & 12-x & 2011 \\
Provespa & anomala & Thailand & Trang Nayong, Khaozong Lab & 4-ix & 2006 \\
Vespula & germanica & France & Picardie, St-Pierre-Aigle, Chafosse & 17-24-vii & 2011 \\
Chartergellus & amazonicus & Brazil & AM-Manaus, Reserva F. Adolfo Ducke & 10-viii & 2010 \\
Clypearia & weyrauchi & Brazil & AM-Manaus, Reserva F. Adolfo Ducke & 10-viii & 2010 \\
Brachygastra & lecheguana & Brazil & RS, Santa Cruz do Sul & 26-xii & 2009 \\
Polistes & versicolor & Brazil & RS, Santa Cruz do Sul & 26-xii & 2009 \\
Apoica & arborea & Brazil & AM-Manaus, Reserva F. Adolfo Ducke & 10-viii & 2010
\end{tabular}




$\begin{array}{llllrl}\text { Parapolybia } & \text { varia } & \text { Papua } & \text { Mount Wilhelm } & 28-\mathrm{x} & 2012 \\ \text { Belonogaster } & \text { freyi } & \text { South Africa } & \text { Sun City } & 23-\mathrm{i} & 2006 \\ \text { Polistes } & \text { tepidus } & \text { Papua } & \text { Mount Wilhelm } & 5-\mathrm{xi} & 2012 \\ \text { Ropalidia } & \text { maculiventris } & \text { Papua } & \text { Mount Wilhelm } & 3-\mathrm{xi} & 2012 \\ \text { Polybia } & \text { rejecta } & \text { Brazil } & \text { AM-Manaus, Reserva F. Adolfo Ducke } & \text { 10-viii } & 2010 \\ \text { Agelaia } & \text { multipicta } & \text { Brazil } & \text { RS, Santa Cruz do Sul } & 26-30 \text {-xii } & 2009 \\ \text { Mischocyttarus } & \text { drewseni } & \text { Brazil } & \text { RS, Santa Cruz do Sul } & \text { 26-30-xii } & 2009\end{array}$
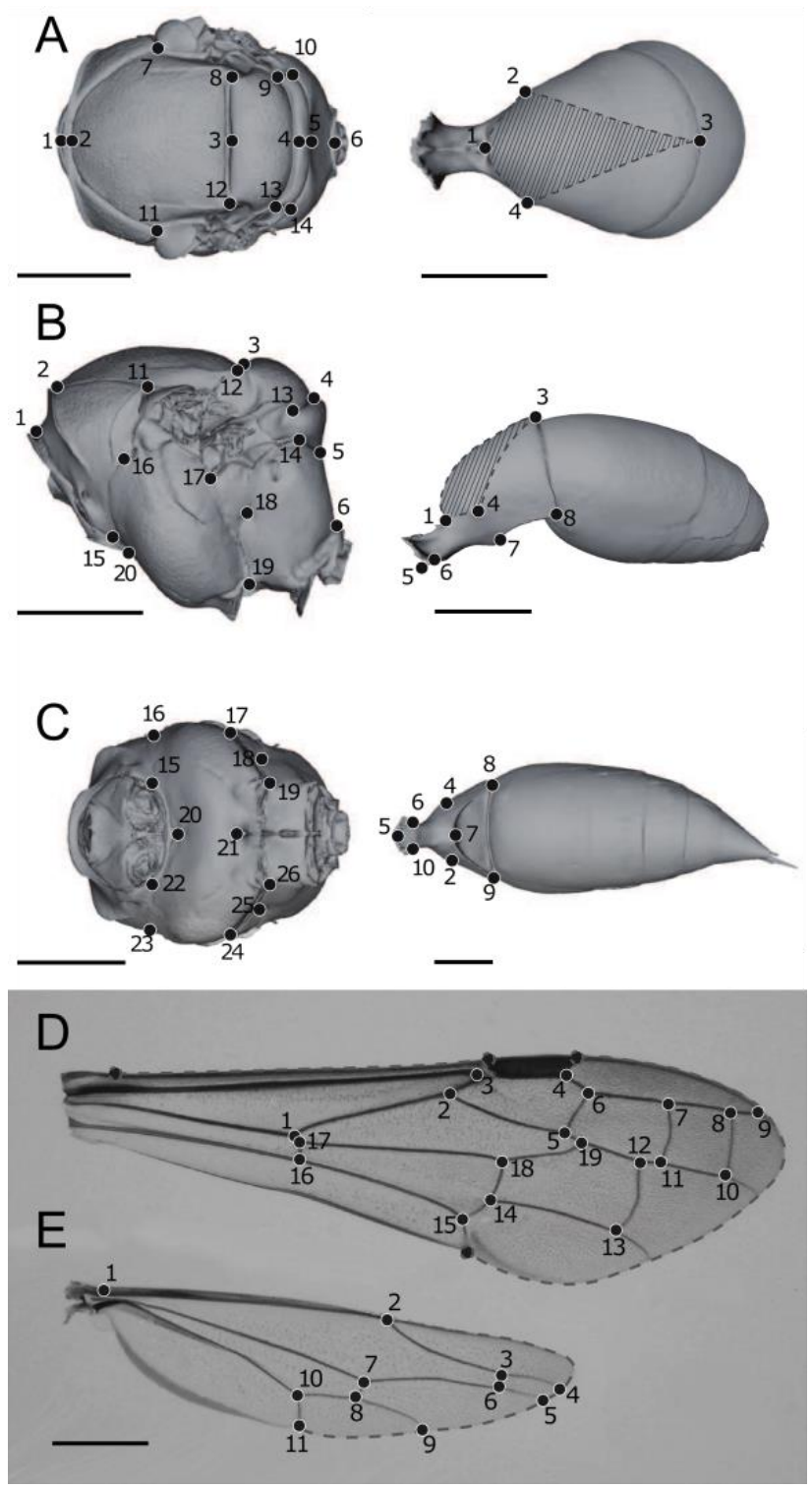
Figure A1. Location of the landmarks and semi-landmarks on the mesosoma (left) and first metasomal tergum (right), and on the wings. A. Dorsal view. B. Lateral view (left). C. ventral view. D. Forewing. E. Hindwing. Circles indicate fixed, anatomical landmarks. Dotted lines and striped area indicate semilandmarks. For A, B and C, the insect is facing left. Illustrations are not at the same scale. Scale: $2 \mathrm{~mm}$.

The phylogeny and associated relative branch lengths used in the study were retrieved from the maximum likelihood tree of Vespidae inferred from 235 selected loci sequenced across 163 taxa published by Piekarski and his collaborators (2018). From this tree, the 22 closest relatives of the species measured in this study were selected (Table A2). Other species were then pruned from the tree. The tree was timecalibrated using Penalized Likelihood using the 'chronos' function from the 'ape' library in R following a correlated model, with lambda $=1$ (Paradis et al. 2004). In order to refine the process, the age estimation of four of the nodes was bounded using current fossil knowledge from the family Vespidae:

- The root was bounded between 145 and 129.4 Mya: no Vespidae is known from the Jurassic. In the meantime, the lineage of the Stenogastrinae was already separated from the other Vespidae at the Hauterivian, (129.4 Mya; Carpenter and Rasnitsyn, 1990, Perrard et al. 2017).

- The oldest Odynerini fossil was known from the Turonian (89.8 Mya; Carpenter, 2000). Odynerini being paraphyletic with Eumenini based on Piekarski et al. 2018, this information was used as a boundary for the node distinguishing the lineage (Odynerini+Eumenini) from the other species. The older boundary used was left high, to the Hauterivian (129), no Eumeninae, Polistinae or Vespinae being observed from this age, despite other lineages of Vespidae being represented in early cretaceous deposits (Carpenter and Rasnitsyn, 1990).

- Confirmed Polistinae and Eumenini were found in the Paleocene (Piton, 1940). The younger boundary of the two nodes distinguishing this subfamily and this tribe from their sister group was therefore set to the younger boundary of Paleocene (estimated at 56Mya). The older boundary was set at the Turonian.

While there are fossils of some of the genera studied here, the younger nodes were not used for calibration due to the lack of confidence in the identification of the fossils to the genus level. 
Table A2. Voucher species and corresponding taxon used from the phylogeny.

This study

Eustenogaster calyptodoma

Delta latreillei

Euodynerus leucomelas

Abispa ephippium

Eumenes sp.

Zethus slossonae

Dolichovespula arenaria

Vespa affinis

Provespa anomala

Vespula germanica

Chartergellus amazonicus

Clypearia weyrauchi

Brachygastra lecheguana

Polistes (Gyrostoma) tepidus

Polistes (Aphanilopterus) versicolor

Apoica arborea

Parapolybia varia

Belonogaster freyi

Ropalidia maculiventris

Polybia rejecta

Agelaia multipicta
Piekarski et al. 2018

Eustenogaster hauxwellii

Delta esuriens

Euodynerus hidalgo

Abispa ephippium

Eumenes crucifera

Zethus slossonae

Dolichovespula arenaria

Vespa velutina

Provespa barthelemyi

Vespula vulgaris

Chartergellus amazonicus

Clypearia duckei

Brachygastra bilineolata

Polistes (Gyrostoma) schach

Polistes (Aphanilopterus) buyssoni

Apoica pallida

Parapolybia indica

Belonogaster prasina

Ropalidia festina

Polybia jurinei

Agelaia testacea 


\section{References Cited Only in the Online Enhancements}

Carpenter, J. M., \& Rasnitsyn, A. P. (1990). Mesozoic Vespidae. Psyche, 97(1-2), 1-20.

Carpenter J. M. (2000). A vespid wasp from New Jersey Cretaceous amber. In Grimaldi D. A. (ed.) Studies on fossils in amber, with particular reference to the Cretaceous of New Jersey, 333-37. Leiden, The Netherlands: Backhuys.

Perrard, A., Grimaldi, D., \& Carpenter, J. M. (2017). Early lineages of Vespidae (Hymenoptera) in Cretaceous amber. Systematic Entomology, 42(2), 379-386.

Piekarski, P. K., Carpenter, J. M., Lemmon, A. R., Moriarty Lemmon, E., Sharanowski, B. J., \& Crandall, K. (2018). Phylogenomic evidence overturns current conceptions of social evolution in wasps (Vespidae). Molecular Biology and Evolution. 35:2097-2109.

Piton, L. E. (1940). Paleontologie du gisement eocene de Menat. Memoires de la societe d'histoire naturelle d'Auvergne, 1, 1-303. 